\title{
A Novel Phenylalanine-Based Targeting Signal Directs Telencephalin to Neuronal Dendrites
}

\author{
Sachiko Mitsui, ${ }^{1}$ Michiko Saito, ${ }^{1}$ Ken Hayashi, ${ }^{1}$ Kensaku Mori, ${ }^{2}$ and Yoshihiro Yoshihara ${ }^{1}$ \\ ${ }^{1}$ Laboratory for Neurobiology of Synapse, RIKEN Brain Science Institute, Wako, Saitama 351-0198, Japan, and 2Department of Physiology, Graduate School \\ of Medicine, University of Tokyo, Tokyo 113-0033, Japan
}

\begin{abstract}
Neurons sort out a variety of functional molecules to appropriate subcellular destinations. Telencephalin (TLCN; intercellular adhesion molecule-5) is a cell adhesion molecule specifically localized to somatodendritic membranes in the telencephalic neurons. Here, we established a new in vivo strategy to analyze neuronal sorting mechanisms by ectopic expression of molecules of interest in the cerebellar Purkinje cells of transgenic mice. By using this system, we identified a novel dendritic targeting determinant in the cytoplasmic tail region of TLCN. A full-length TLCN ectopically expressed in the Purkinje cells was localized exclusively to dendrites but not to axons. In contrast, a deletion of cytoplasmic C-terminal 12 amino acids (residues 901-912) or a point mutation of Phe905 to Ala abrogated the dendritespecific targeting with appearance of the truncated and point-mutated TLCN in both axons and dendrites. Furthermore, an addition of the C-terminal 17 amino acids (residues 896-912) of TLCN to an unrelated molecule (CD8) was sufficient for its specific targeting to dendrites in several types of neurons. Because the C-terminal region of TLCN does not contain any canonical dendritic targeting sequences such as the tyrosine-based motif or the dileucine motif, this study suggests a novel mechanism of protein trafficking to the dendritic compartment of neurons.
\end{abstract}

Key words: cell adhesion molecule; telencephalin; dendrite; sorting signal; transgenic mouse; Purkinje cells

\section{Introduction}

Neurons are polarized with two distinct processes: axons and dendrites (Craig and Banker, 1994). Axons and dendrites differ in morphology, function, and molecular constituents, and most importantly, they determine the direction of signal transmission via synapses. Formation, maintenance, and plasticity of the synaptic connections between axons and dendrites require polarized sorting of functional proteins to appropriate subcellular compartments (Winckler and Mellman, 1999). Thus, it is important to clarify molecular mechanisms that regulate targeting of specific proteins to dendrites or axons.

Dendrites play a key role as postsynaptic sites in neurotransmission and integration of numerous synaptic inputs. Several mechanisms have been postulated for the dendrite-specific targeting of functional molecules (Dotti and Simons, 1990; Craig and Banker, 1994; Winckler and Mellman, 1999). Particularly, two specific sequence motifs in the cytoplasmic domain of various proteins have been highlighted as dendritic targeting signals. One is a tyrosine-based motif characterized by an essential tyrosine in the context of YXXФ (where X represents any amino

Received Sept. 16, 2004; revised Dec. 13, 2004; accepted Dec. 16, 2004.

This work was supported in part by the Special Coordination Funds for Promoting Science and Technology from the Japan Science and Technology Corporation and by a Grant-in-Aid for Scientific Research on Priority Areas (C)Advance Brain Science Project from the Ministry of Education, Culture, Sports, Science and Technology of Japan. We thank Dr. Harry T. Orr for mouse L7 promoter, members of the Brain Science Institute Research Resource Center for generation and maintenance of transgenic mice, and members of the Yoshihara laboratory for helpful discussions.

Correspondence should be addressed to Dr. Yoshihiro Yoshihara, Laboratory for Neurobiology of Synapse, RIKEN Brain Science Institute, 2-1 Hirosawa, Wako-shi, Saitama 351-0198, Japan. E-mail: yoshihara@brain.riken.go.jp. DOI:10.1523/JNEUROSCI.3853-04.2005

Copyright $\odot 2005$ Society for Neuroscience $\quad$ 0270-6474/05/251122-10\$15.00/0 acid and $\Phi$ is a bulky hydrophobic residue). Involvement of this motif in the dendritic targeting was reported for low-density lipoprotein receptor (Jareb and Banker, 1998), transferrin receptor (West et al., 1997; Jareb and Banker, 1998), and Delta/Notchlike epidermal growth factor (EGF)-related receptor (Eiraku et al., 2002). The other is a dileucine-based motif characterized by two consecutive leucine residues that are crucial for the dendritic targeting of glycine transporter $1 \mathrm{~b}$ (Poyatos et al., 2000) and potassium channel Kv4.2 (Rivera et al., 2003).

Telencephalin (TLCN) [intercellular adhesion molecule-5 (ICAM-5)] is a cell adhesion molecule belonging to the ICAM subgroup of the Ig superfamily (Mori et al., 1987; Yoshihara and Mori, 1994). The expression of TLCN is restricted to neurons in the most rostral brain segment, telencephalon (Mori et al., 1987; Oka et al., 1990). In the telencephalic neurons, TLCN protein is strictly localized to the somatodendritic compartment but not to axons (Murakami et al., 1991; Benson et al., 1998; Sakurai et al., 1998). The selective sorting of TLCN to dendrites is crucial for the function of TLCN in the formation of dendritic filopodia and negative regulation of spine maturation ( $\mathrm{H}$. Matsuno, K. Mori, and Y. Yoshihara, unpublished data). However, molecular mechanisms that regulate the dendritic targeting of TLCN are not yet known.

TLCN is a glycoprotein consisting of a signal peptide, an extracellular region with nine Ig-like domains, a transmembrane segment, and a short cytoplasmic region with $\sim 60$ amino acids (Yoshihara et al., 1994). We addressed the question of which part of TLCN protein is critical for the dendritic targeting. For this purpose, we developed a transgenic mouse system to express 
TLCN and its mutants in in vivo neurons and immunohistochemically traced the trafficking of protein products. With this system, we identified a crucial element at the most $\mathrm{C}$ terminus of TLCN that functions as a novel type of dendrite-specific sorting signal.

\section{Materials and Methods}

Transgene construction and mutagenesis. To construct pL7-TLCN, full-length rabbit TLCN cDNA (Yoshihara et al., 1994) was inserted into EcoRI site of pBstN-Pcp2 vector (Yoshihara et al., 1999), which contains human $\beta$-globin gene introns and an SV40 polyadenylation signal and mouse L7 (Pcp2) promoter $(3.5 \mathrm{~kb})$ region (Vandaele et al., 1991). Deletion mutants (pL7TLCN $\Delta$ C52, pL7-TLCN $\Delta$ C29, pL7-TLCN $\Delta$ C12) and point mutants (pL7-TLCN-Y861A, pL7TLCN-F905A) of TLCN were constructed by using a site-directed mutagenesis kit (GeneEdition In Vitro Site-Directed Mutagenesis system kit; Promega, Madison, WI) with pL7-TLCN as a template or by introducing an oligonucleotide linker. 3xFLAG tag derived from pIREShrGFP-1a vector (Stratagene, La Jolla, CA) was fused to 3 '-end of rabbit TLCN to generate pL7TLCN/FLAG. Human CD8 cDNA was cloned from human thymus cDNA library (Clontech, Cambridge, UK) and inserted into pBstN-Pcp2 to generate pL7-CD8. Fusion transgenes pL7CD8/TLCN-C61 and pL7-CD8/TLCN-C17 were generated by recombinant PCR-based mutagenesis and by oligonucleotide linker ligation, respectively. Mouse TLCN promoter (4.0 kb) (Sugino et al., 1997) was inserted into BamHI site of pBstN-CD8 and pBstN-CD8/ TLCN to generate pTLCN-CD8 and pTLCNCD8/TLCN. All of the plasmid constructs were sequenced to confirm that no unintended mutations were integrated. The transgenes were excised from the vectors and used for microinjection.

Generation of transgenic mice. The generation of transgenic mice was performed according to Kobayashi et al. (1994). Gel-purified transgenes were microinjected into the pronucleus of fertilized eggs that were obtained from mating $(\mathrm{C} 57 \mathrm{BL} / 6 \mathrm{~J} \times \mathrm{DBA} / 2 \mathrm{~J}) \mathrm{F}_{1}$ mice. The manipulated eggs were cultured to two-cell stage and transferred into oviducts of pseudopregnant foster females (ICR strain). Integration of the transgene was screened by PCR of tail DNA with specific primer pairs for rabbit TLCN or human CD8. All animal experiments were approved by the Animal Care and Use Committee of RIKEN and conformed to National Institutes of Health guidelines.

Immunohistochemistry. Mice were killed with an overdose of sodium pentobarbital (200 mg/ $\mathrm{kg}$, i.p.) and perfused by means of the left ventricle with PBS followed by $4 \%$ paraformaldehyde in $0.1 \mathrm{~m}$ phosphate buffer. Brains were removed, postfixed overnight at $4^{\circ} \mathrm{C}$ in the same fixative, and cryoprotected in $30 \%$ sucrose in PBS. Parasagittal brain sections (50 $\mu \mathrm{m})$ were prepared with a freezing sliding microtome and collected in Tris-buffered saline containing $0.02 \%$ sodium azide.
A

L7 promoter gene of interest

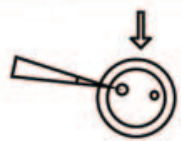

transgene injection
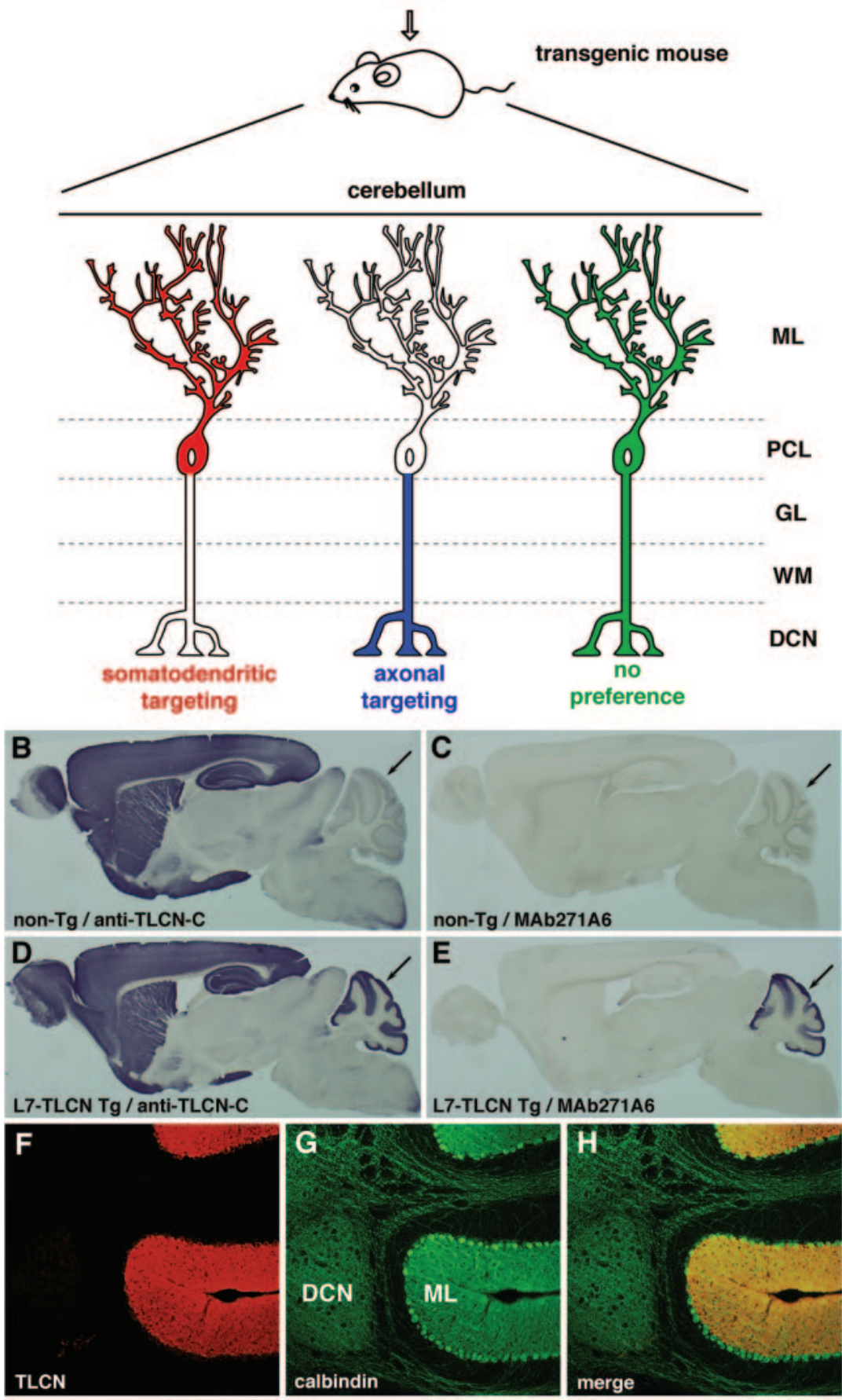

E
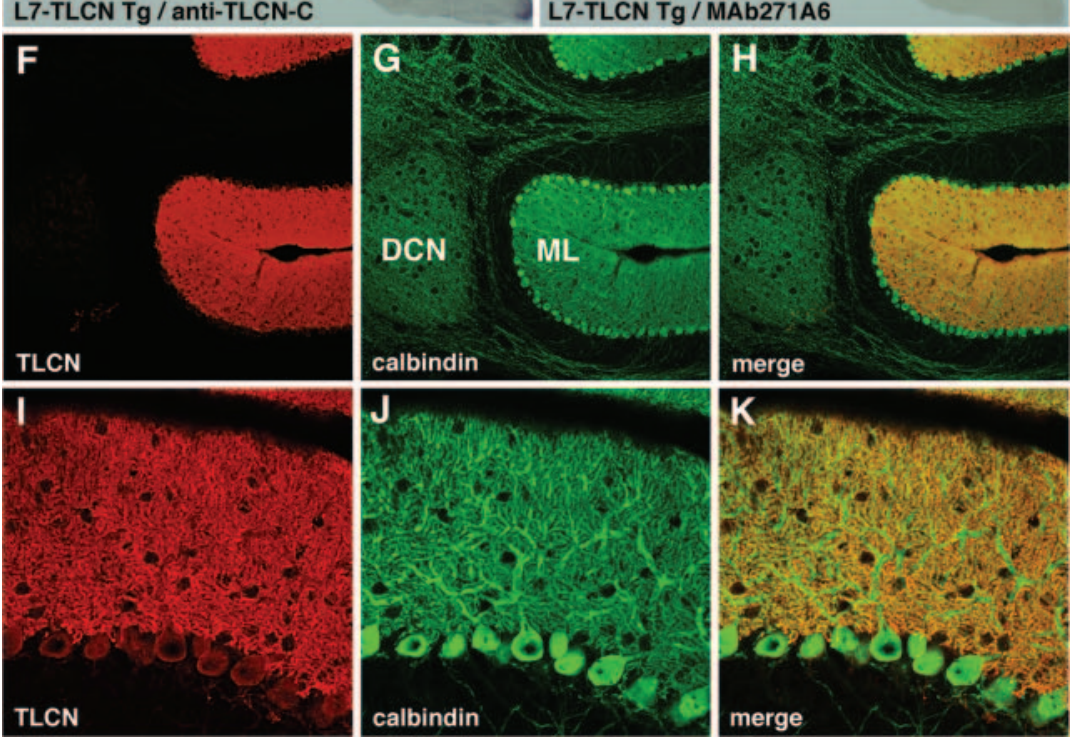
A

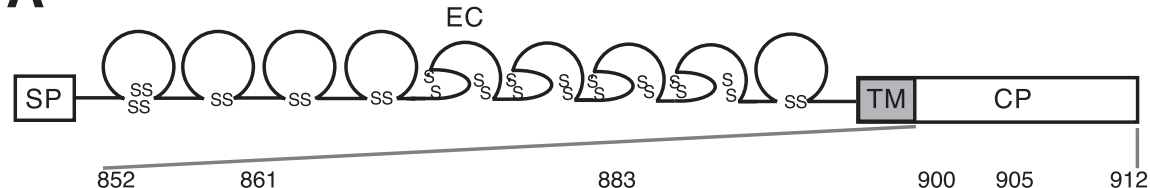

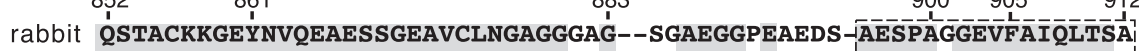
human QSTACKKGEYNVQEAESSGEAVCLNGAGGGAGGAAGAEGGPEAAGGAAESPAEGEVFAIQLTSA mOUSe QSTACKKGEYNVQEAESSGEAVCLNGAGGTPG----AEGGAETPGT_AAESPADGEVFAIQLTSS rat QSTACKKGEYNVQEAESSGEAVCLNGAGGTPG----AEGGAETPGT-AESPADGEVFAIOLTSS

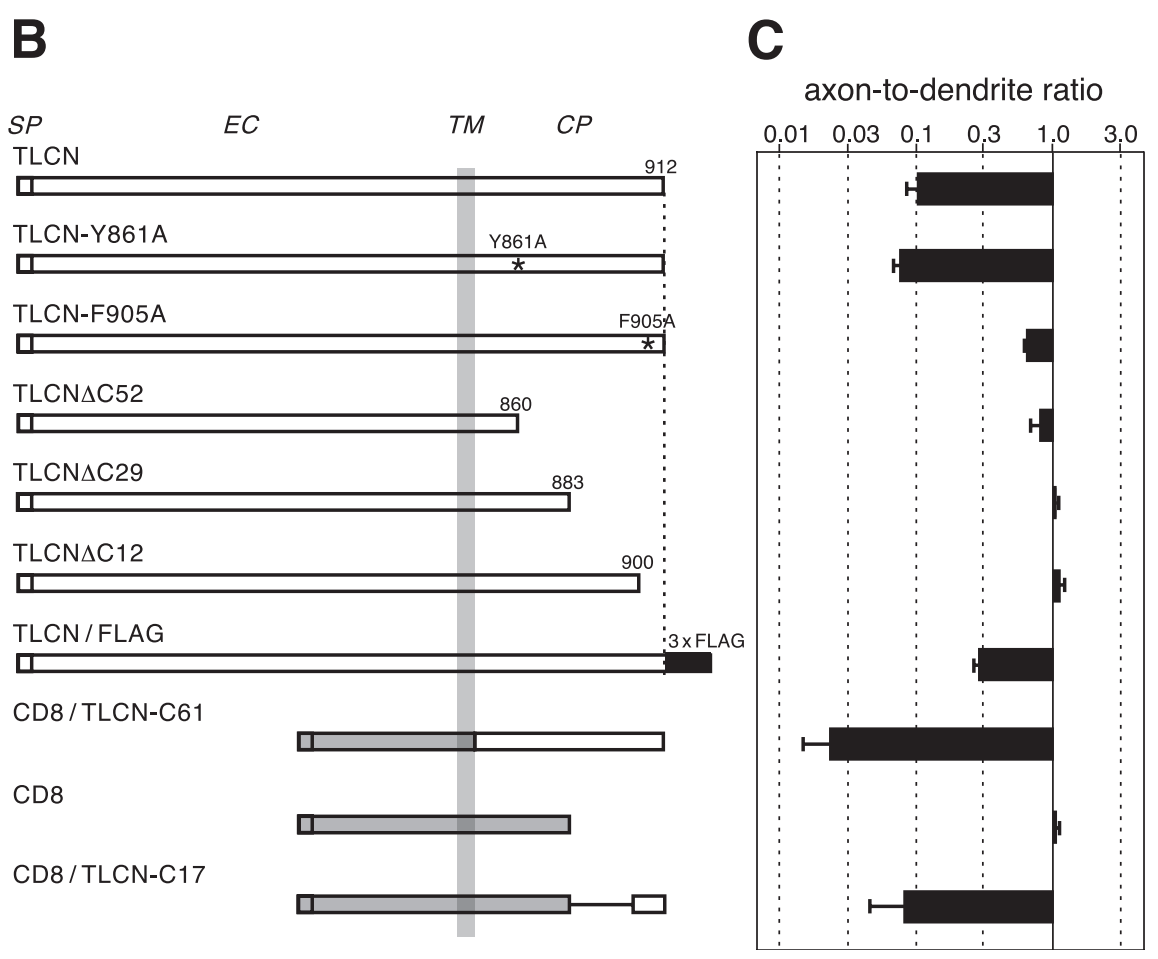

Figure 2. Schematic representation of TLCN and its mutants used in this study. A, Domain structure of TLCN and amino acid sequence alignment of its cytoplasmic region. TLCN comprises the N-terminal signal peptide (SP), a long extracellular region (EC) with nine Ig-like domains, a transmembrane segment (TM), and a short cytoplasmic tail (CP). Disulfide bonds in the Ig-like domains are indicated by ss. The cytoplasmic domain of TLCN is highly conserved across various mammalian species (rabbit, human, mouse, and rat). Gray shading represents conserved amino acid residues in at least three of the four species. $B$, Schematic diagrams of native TLCN, point mutants (TLCN-Y861A, TLCN-F905A), C-terminus-truncated mutants (TLCN $\Delta C 52$, TLCN $\Delta C 29$, TLCN $\Delta$ C12), C-terminus-masked mutant (TLCN/FLAG), chimeric mutants (CD8/TLCN-C61, CD8/TLCN-C17), and native CD8. The asterisks indicate the sites of point mutations. C, ADR for transgene products expressed in Purkinje cells. This graph summarizes quantitative analysis of the polarized localization for individual proteins. Lower values of $\operatorname{ADR}(\sim 0.1)$ indicate selective localization of proteins to dendrites, whereas the ADR for nonpolarized proteins averages 1 theoretically.

$\leftarrow$

Figure 1. Dendritic targeting of full-length TLCN ectopically expressed in the cerebellar Purkinje cells. A, A schematic diagram of a novel transgenic mouse system for analyzing neuronal targeting mechanism. A transgene consisting of mouse $L 7$ promoter $(\sim 3 \mathrm{~kb})$, a gene of interest, and polyadenylation signal $(\mathrm{pA})$ is injected into the pronuclei of fertilized eggs to generate transgenic mouse founders and lines. The transgene products are expressed in Purkinje cells of the cerebellum. If the transgene products were specifically sorted into a somatodendritic compartment, its immunoreactivity should be observed in the ML and PCL (red). In contrast, axonal proteins should be detected in the GL, WM, and DCN (blue). Nonpreferential targeting of the transgene products should result in the appearance in all of the layers (green). $B-E$, Immunohistochemical detection of endogenous mouse TLCN and transgene-derived rabbit TLCN. The endogenous TLCN recognized by rabbit anti-TLCN-C antiserum is specifically expressed in neurons within the telencephalon (the most rostral brain segment) of both nontransgenic $(B)$ and L7-TLCN transgenic $(D)$ mice. The transgene-derived rabbit TLCN is recognized by both rabbit anti-TLCN-C antiserum $(D)$ and mouse MAb271A6 (E). The rabbit TLCN is detected in the cerebellum (arrows) of L7-TLCN transgenic mouse $(D, E)$ but not in nontransgenic mouse $(B, C)$. F-K, Double-immunofluorescence labeling of TLCN (red) and calbindin (green) in the cerebellum of L7-TLCN transgenic mouse. Fulllength TLCN is detected in the ML but not in the DCN $(F-H)$, indicating its dendrite-specific targeting. A high-power view shows that TLCN is preferentially localized to dendrites rather than soma of Purkinje cells $(I-K)$.
For light-microscopy immunohistochemistry, the sections were pretreated for 30-60 min in $\mathrm{PBS}$ containing $0.3 \% \mathrm{H}_{2} \mathrm{O}_{2}$ to eliminate endogenous peroxidase activity. They were washed in PBS three times for 5-10 min, incubated for $1 \mathrm{~h}$ in $5 \%$ normal goat serum (NGS) in PBS containing $0.2 \%$ Triton X-100 (PBST), and then incubated overnight at room temperature with either of two primary antibodies against TLCN. To label endogenous TLCN, we used a rabbit polyclonal antibody (anti-TLCN-C antiserum; 10,000X) raised against a synthetic peptide corresponding to the $\mathrm{C}$-terminal 17 amino acids in the intracellular region of mouse TLCN (Sakurai et al., 1998). To detect transgenederived rabbit TLCN and its mutants, we used a mouse monoclonal antibody (MAb271A6 ascites; $1000-1500 \times$ ) that recognizes the extracellular region of rabbit TLCN but not mouse TLCN (Mori et al., 1987; Yoshihara et al., 1994). The sections were washed in PBST/NGS three times for 5-10 min, incubated for $1 \mathrm{~h}$ with horseradish peroxidase-conjugated secondary antibody (300×; Jackson ImmunoResearch, West Grove, PA), and washed similarly. After rinsing in PBS followed by $50 \mathrm{~mm}$ Tri- $\mathrm{HCl}$ buffer, $\mathrm{pH}$ 7.6, the sections were incubated in $0.1 \%$ diaminobenzidine tetrahydrochloride (Wako Pure Chemical Industries, Osaka, Japan) and $0.6 \% \mathrm{Ni}^{2+}$ ammonium sulfate (Nacalai Tesque, Kyoto, Japan) in $50 \mathrm{~mm}$ Tris- $\mathrm{HCl}$, $\mathrm{pH}$ 7.6, containing $0.02 \% \mathrm{H}_{2} \mathrm{O}_{2}$ for 5-15 min. Finally, the sections were washed in PBS, dried overnight, dehydrated in a graded series of ethanol, soaked in D-limonene (Hemo-De; Fujisawa Pharmaceutical, Osaka, Japan), and coverslipped with Mount-Quick (Daido Sangyo, Saitama, Japan). Specimens were observed by using a light microscope (Olympus, Tokyo, Japan) equipped with a cooled CCD camera (Sony, Tokyo, Japan) and an image analysis system (Adobe Photoshop; Adobe Systems, San Jose, CA).

For double-immunofluorescence labeling, brain sections were pretreated with PBST/NGS for $30 \mathrm{~min}$, incubated overnight with either MAb271A6 (1000-1500 $\times$ ) or mouse monoclonal anti-human CD8 antibody (HIT8a; $1000 \times$; BD Biosciences, Franklin Lake, NJ) in PBST/NGS, washed, and incubated with Cy3labeled goat anti-mouse IgG (300×; Jackson ImmunoResearch) for $1 \mathrm{~h}$. The sections were washed, incubated with either rabbit anticalbindin antibody (1000×; Chemicon, Temecula, CA) or rabbit anti-substance $\mathrm{P}$ antibody (1000×; DiaSorin, Stillwater, MN) for $4 \mathrm{~h}$, washed, incubated with Alexa488-labeled goat anti-rabbit IgG (300×; Molecular Probes, Eugene, OR), washed, coverslipped with Vectashield (Vector Laboratories, Burlingame, CA), and examined with a confocal laserscanning microscope (Radiance 2000; Bio-Rad, Hercules, CA).

Image analysis. We measured fluorescence intensity of anti-TLCN or anti-CD8 immunoreactivity [transgene products (TPs)] and anticalbindin immunoreactivity (internal standard) in dendrites and axons. The average fluorescence intensity in dendrites and axons 
was obtained from more than three immunostained sections for each mouse by randomly drawing three one-pixel-wide lines encompassing from the molecular layer (ML) to the deep cerebellar nuclei (DCN) on collected digital images using NIH Image software. Because calbindin is present throughout the cytoplasm in both axons and dendrites of Purkinje cells, we used it as an internal standard. With reference to Rivera et al. (2003) and Cheng et al. (2002), we quantified the degree of polarized distribution of transgene products and defined the axon-to-dendrite ratio (ADR). The ADR was calculated by the following equation: $\mathrm{ADR}=\left(\mathrm{TP}_{\text {axon }} / \mathrm{TP}_{\text {dendrite }}\right) /\left(\right.$ calbindin $_{\text {axon }} /$ calbindin dendrite $)$, where $\mathrm{TP}_{\text {axon }}$ and $\mathrm{TP}_{\text {dendrite }}$ are the relative amount of the transgene product in the axons and dendrites, respectively, and calbindin $_{\text {axon }}$ and calbindin dendrite are the relative amount of calbindin in the axons and dendrites, respectively. The data were obtained from more than three different mice for individual transgene constructs and represented as mean \pm SEM.

Cell culture, transfection, and immunocytochemistry. Transgenes (CD8, CD8/TLCN-C17, CD8 $\Delta$ Ct, CF8/TLCN-C61, CD8/TLCN $\Delta$ C29) (see Fig. 7) were subcloned into a bicistronic mammalian expression vector, pIRES2-EGFP (Clontech). Madin-Darby canine kidney (MDCK) epithelial cells were maintained in DMEM supplemented with $10 \%$ fetal bovine serum (Invitrogen, Carlsbad, CA), $100 \mathrm{U} / \mathrm{ml}$ penicillin, and $100 \mu \mathrm{g} / \mathrm{ml}$ streptomycin in $5 \%$ $\mathrm{CO}_{2}$ at $37^{\circ} \mathrm{C}$. One day before transfection, the cells were plated at high density onto $12 \mathrm{~mm}$ Transwell filters (Corning, New York, NY). Plasmid transfection was performed using LipofectAMINE 2000 (Invitrogen) according to the instructions of the manufacturer. The cells on Transwell filters were allowed to grow to confluency for $48 \mathrm{~h}$ after the transfection.

The cells were rinsed in PBS, fixed in $3.8 \%$ formalin in PBS for $10 \mathrm{~min}$, washed twice in PBS, permeabilized in $0.2 \%$ Triton X-100 in PBS for $5 \mathrm{~min}$, washed three times, and incubated with anti-CD8 antibody (HIT8a; 1000×) for $1-2 \mathrm{~h}$, washed three times, incubated with Cy3-labeled goat anti-mouse IgG (300×), and washed three times. The filters with stained cells were carefully removed from Transwells, mounted onto the slide glass, and coverslipped in Vectashield (Vector Laboratories). The specimens were observed with the confocal laserscanning microscopy (Radiance 2000; Bio$\mathrm{Rad})$, and $\mathrm{z}$-series line scanning images were constructed.

\section{Results}

Selective dendritic targeting of fulllength TLCN in Purkinje cells

A novel transgenic mouse strategy was developed, which enabled us to analyze polarized sorting of molecules in neurons with high accuracy and reproducibility (Fig. 1A). Expression of endogenous TLCN is restricted within the telencephalon, and cerebellar Purkinje cells do not
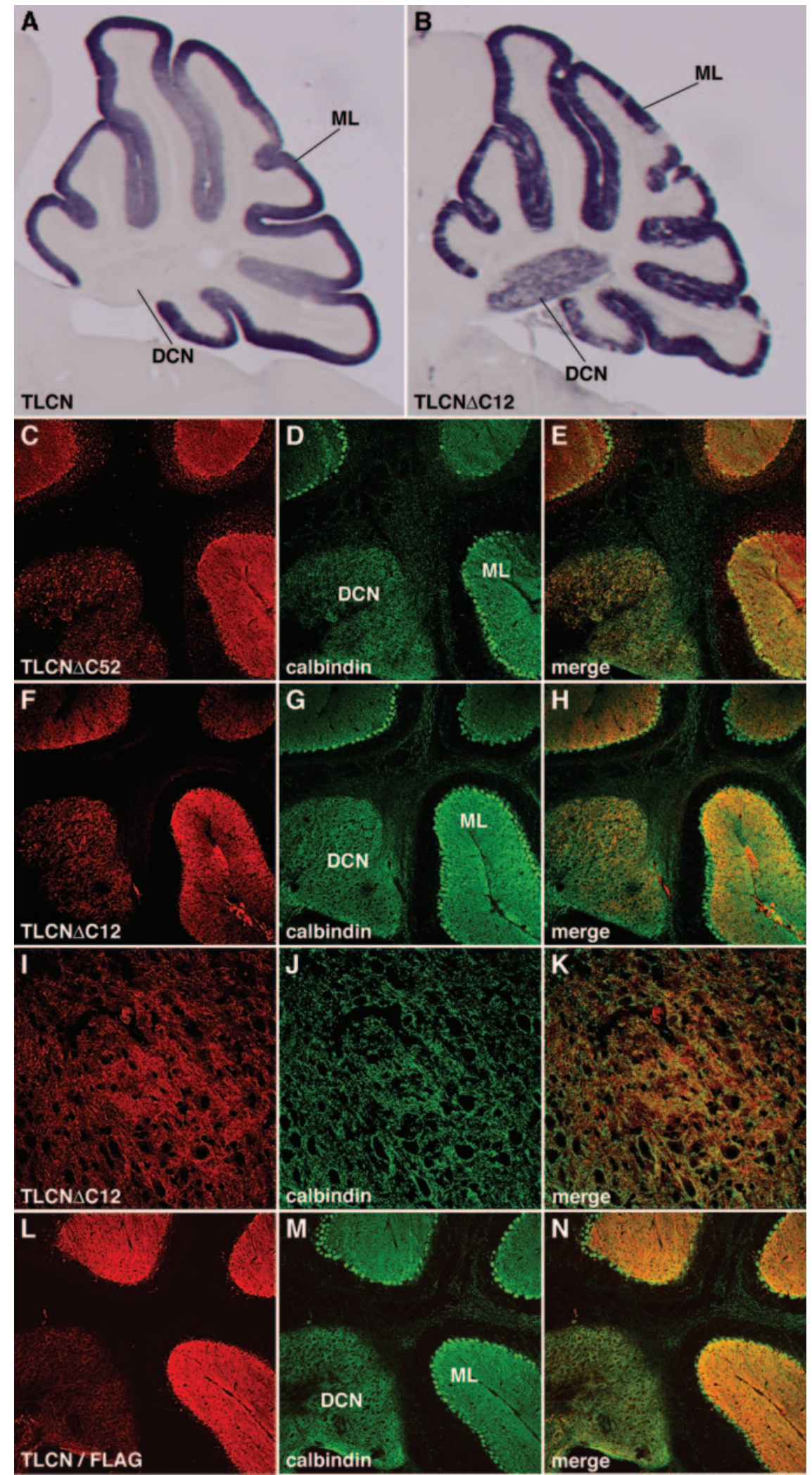

Figure 3. Importance of the $C$ terminus of TLCN for its dendritic targeting. $A, B$, Anti-rabbit TLCN (MAb271A6)-labeled parasagittal sections of transgenic mouse cerebellum ectopically expressing full-length TLCN $(A)$ or C-terminus-truncated TLCN (TLCN $\Delta C 12)(B)$. Note the appearance of TLCN $\Delta C 12$, but not full-length TLCN, in the DCN, indicating the abolishment of dendritic targeting by the $C$-terminus deletion. $C-N$, Double immunofluorescence labeling of parasagittal sections of the transgenic mouse cerebellum with anti-rabbit TLCN (red) and anti-calbindin (green) antibodies. C-E, TLCN $\Delta C 52 . F-K$, TLCN $\Delta C 12 . L-N$, TLCN/FLAG. C-terminus-truncated TLCN (TLCN $\Delta$ C52 and TLCN $\Delta$ C12) and C-terminus-masked TLCN (TLCN/FLAG) are detected not only in the ML but also in the DCN. I-K, A high-power view of DCN in F-H clearly shows the appearance of TLCN $\Delta C 12$ in the axonal terminals of Purkinje cells surrounding the soma of DCN neurons. 

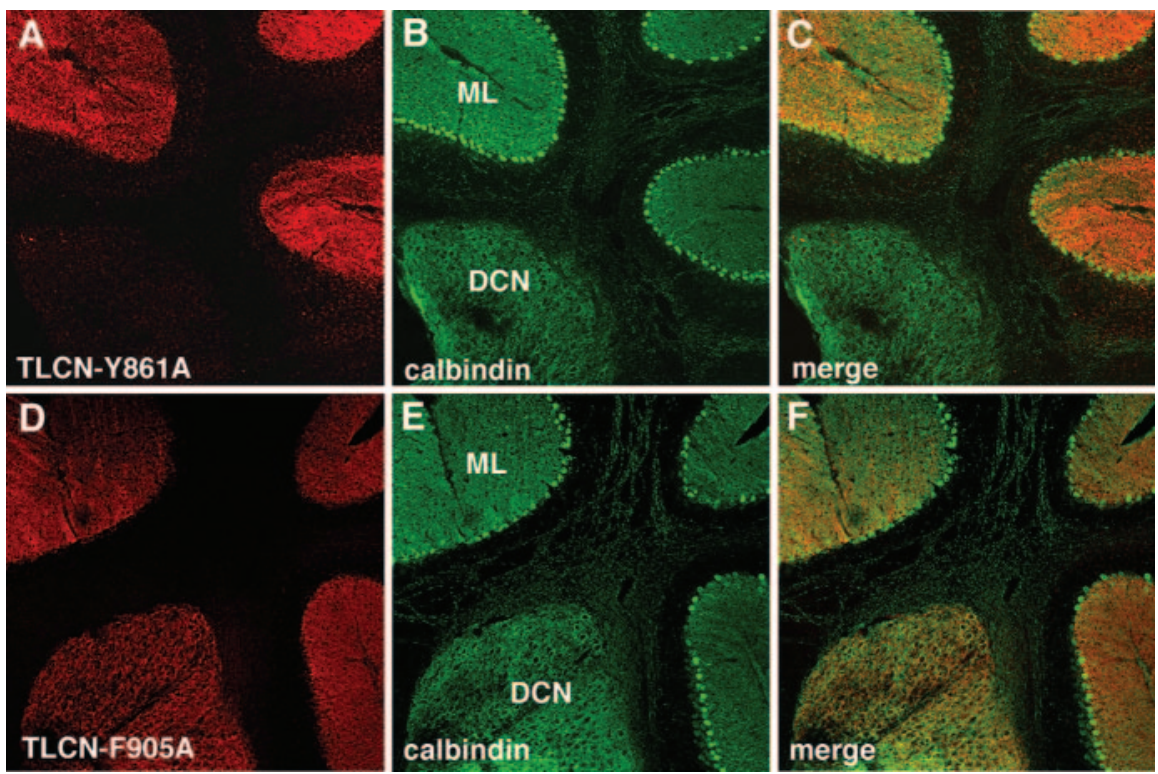

Figure 4. Importance of Phe905 of TLCN for its dendritic targeting. Double-immunofluorescence labeling of parasagittal sections of the transgenic mouse cerebellum with anti-rabbit TLCN (red) and anti-calbindin (green) antibodies is shown. A-C, TLCN-Y861A. The transgene product is detected in ML but not in DCN, suggesting that Tyr861 does not serve for dendritic targeting. D-F, TLCN-F905A. The transgene product is detected in both ML and DCN, suggesting that Phe 905 is a crucial residue for dendritic targeting.
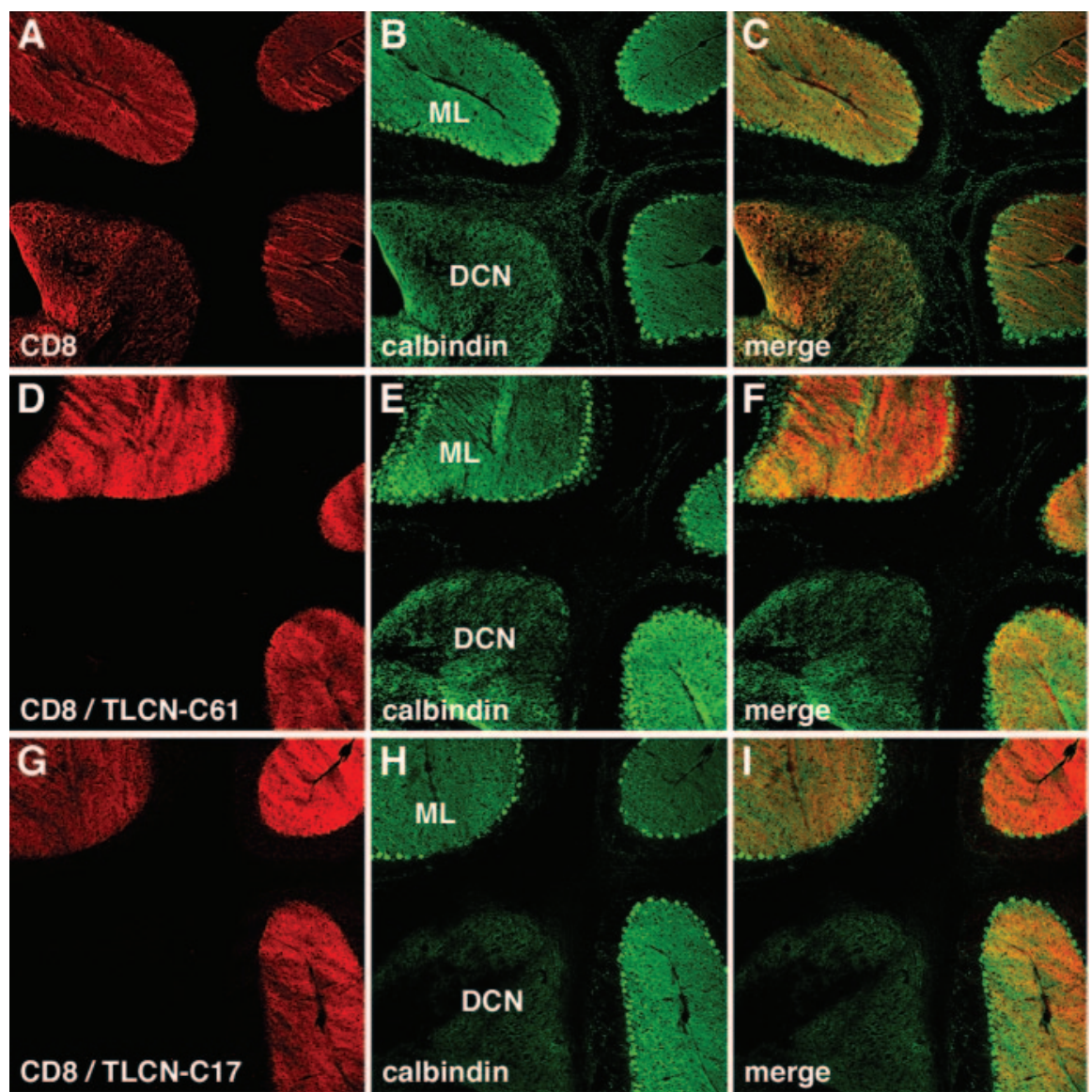

Figure 5. C-terminal region of TLCN suffices dendritic targeting in Purkinje cells. Double-immunofluorescence labeling of parasagittal sections of the transgenic mouse cerebellum with anti-CD8 (red) and anti-calbindin (green) antibodies is shown. $A-C$, CD8. The transgene product is detected in both ML and DCN, indicating no preference of native CD8 protein in dendritic or axonal targeting. $D-F, C D 8 / T L C N-C 61$. The transgene product is detected in ML but not in DCN, indicating that the cytoplasmic domain of TLCN confers dendritic targeting on CD8. G-I, CD8/TLCN-C17. The transgene product is detected in ML but not in DCN, suggesting that the C-terminal 17 amino acid sequence is sufficient for dendritic targeting. express TLCN. We thus used Purkinje cells as a model neuron for the ectopic expression of TLCN. Purkinje cells are advantageous to the immunohistochemical examination of protein sorting, because their dendritic field is spatially segregated from the axonal field (Fig. 1A). Purkinje cells of which cell bodies are located in the Purkinje cell layer (PCL) extend fan-shaped, well elaborated, and spine-bearing dendrites in the ML. In the opposite direction, Purkinje cells project a single axon through the granular layer (GL) and white matter (WM) into the DCN (Altman and Bayer, 1996). Accordingly, the immunoreactivity in the ML indicates the dendritic localization, whereas the labeling in the DCN represents axonal localization. Thus, we can easily and reliably determine the dendritic or axonal localization of molecules in Purkinje cells. To express TLCN in Purkinje cells, we used the mouse L7 gene promoter $(\sim 3 \mathrm{~kb})$. This promoter can efficiently drive the expression of foreign genes in Purkinje cells in a highly specific manner (Oberdick et al., 1990; Vandaele et al., 1991; Yoshihara et al., 1999).

The feasibility of this system was assessed by ectopic expression of full-length rabbit TLCN in Purkinje cells under the control of L7 promoter in transgenic mice. To detect TLCN protein, we used two different anti-TLCN antibodies. One is a polyclonal antibody raised against the intracellular C-terminal peptide of mouse TLCN (anti-TLCN-C) that cross-reacts with rabbit TLCN (Sakurai et al., 1998). The other is MAb271A6 that recognizes a species-specific epitope in the extracellular region of rabbit TLCN (Mori et al., 1987). In the present study, MAb271A6 was mostly used to detect the ectopically expressed rabbit TLCN in transgenic mice.

Parasagittal brain sections of a nontransgenic mouse were immunohistochemically stained with anti-TLCN-C (Fig. $1 B$ ) and MAb271A6 (Fig. 1C). As reported previously (Mori et al., 1987; Oka et al., 1990; Yoshihara et al., 1994; Sakurai et al., 1998), the endogenous TLCN was confined within gray matter of the telencephalon, confirming the selective localization of TLCN in dendrites of telencephalic neurons but not in axons (Fig. 1B). The endogenous mouse TLCN was not recognized by MAb271A6 (Fig. 1C).

When the full-length rabbit TLCN was expressed in Purkinje cells, it was localized to the ML and PCL of the cerebellar cortex but not to the GL, WM, and DCN (Fig. $1 D-F, I)$. Double-immunofluorescence labeling with anti-calbindin antibody, a marker for Purkinje cells, revealed the re- 

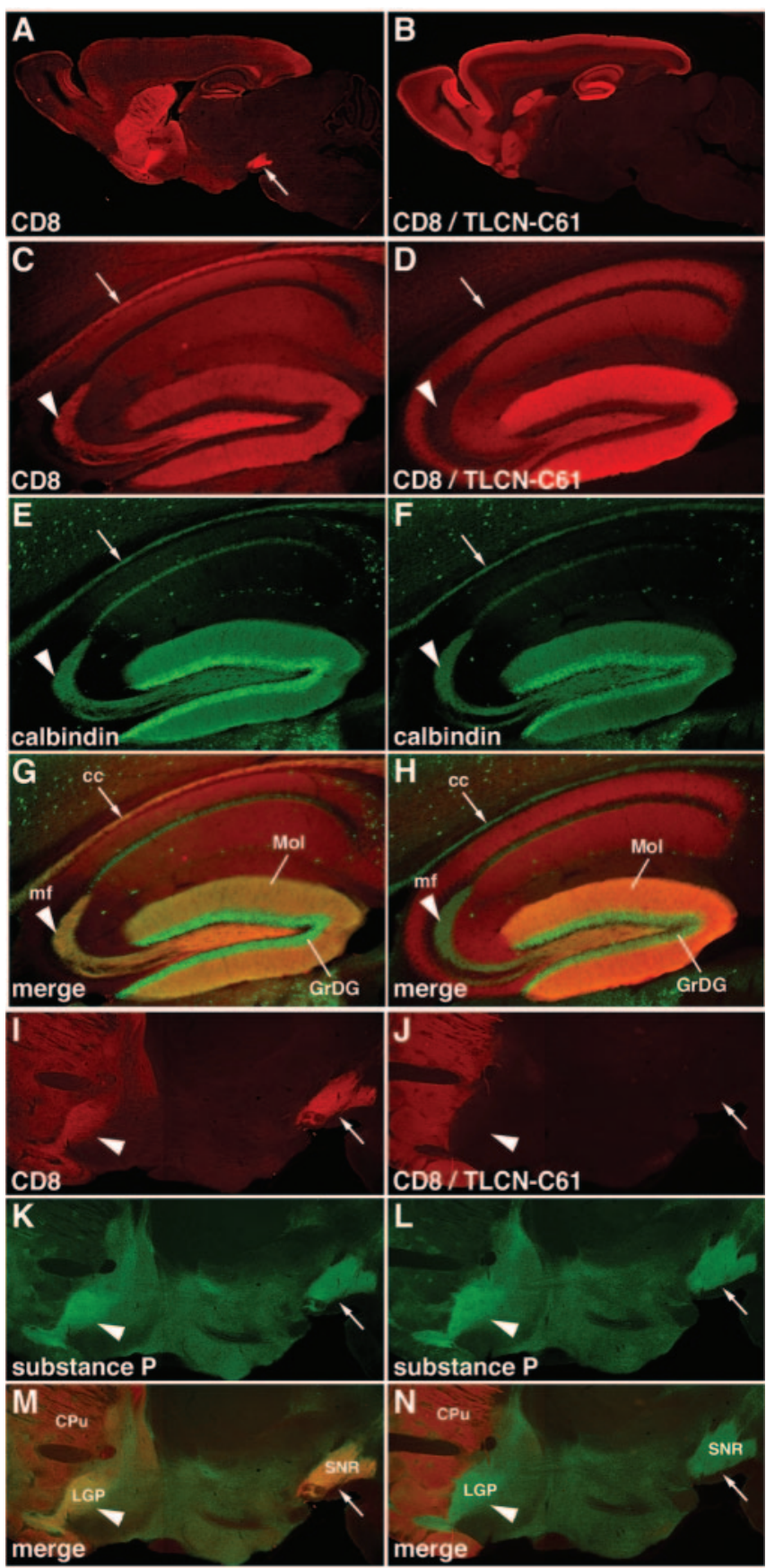

Figure 6. Cytoplasmic region of TLCN suffices dendritic targeting in telencephalic neurons. In this experiment, the transgenes, $\operatorname{CD} 8(A, C, G, I, M)$ or $\operatorname{CD} 8 / \operatorname{TLCN}(B, D, H, J, N)$, were expressed in the telencephalic neurons under the control of TLCN promoter. $A, B$, Parasagittal brain sections labeled with anti-CD8 antibody. Both CD8 $(A)$ and $C D 8 / T L C N ~(B)$ expressions are confined to the telencephalon, except for CD8 immunoreactivity in the substantia nigra $(A$, arrow). $C-H$, Double immunofluorescence labeling of parasagittal sections of the transgenic mouse hippocampus with antiCD8 (red) and anti-calbindin (green) antibodies. Granule cells in the dentate gyrus project their axons (mossy fibers: $(-H$, arrowheads) that are positive for calbindin ( $E-H)$. CD8 is observed in both dendrites and axons of the dentate granule cells $(C, G)$, whereas $C D 8 / T L C N$ is detected only in dendrites but not in axons $(D, H)$. In addition, axons in the corpus callosum are positive only for CD8 but not for CD8/TLCN (C $-H$, arrows). I-N, Double-immunofluorescence labeling of parasagittal sections of the transgenic mouse brain with anti-CD8 (red) and anti-substance $P$ (green) antibodies. Substance $P$ is used for a marker of medium spiny neurons in the caudate-putamen ( $\mathrm{CPu}$ ) that project their axons to the substantia nigra in midbrain (SNR) (I-N, arrows) and the lateral globus pallidus (LGP) in diencephalon. CD8 is observed in axons projecting from CPu to SNR and LGP $(I, M)$, whereas CD8/TLCN is confined to $\mathrm{CPu}$. stricted appearance of TLCN protein in dendrites but not in axonal terminals in the DCN (Fig. $1 F-K$ ). The result suggests that rabbit TLCN ectopically expressed in Purkinje cells underwent selective targeting into dendrites and that Purkinje cells are equipped with the molecular machinery for dendritic trafficking of TLCN similar to that of the TLCN-expressing neurons in the telencephalon. In addition, these data demonstrate that this in vivo system is feasible for the analysis of polarized targeting in neurons.

\section{Cytoplasmic C-terminal region of TLCN is necessary for dendritic targeting}

Most of the dendritic sorting signals identified in transmembrane proteins thus far are located in their cytoplasmic regions (West et al., 1997; Jareb and Banker, 1998; Poyatos et al., 2000; Eiraku et al., 2002; Rivera et al., 2003). The cytoplasmic region of TLCN consists of $\sim 60$ amino acids that are highly conserved across animal species (Fig. 2A). We constructed three serial C-terminus-truncated mutants, TLCN $\Delta$ C52, TLCN $\Delta$ C29, and TLCN $\Delta$ C12 that lack 52, 29, or 12 amino acid residues of the cytoplasmic tail of TLCN, respectively (Fig. 2 B). Several lines of transgenic mice for these constructs were generated and examined to determine whether the dendrite-specific sorting signal was still retained in these deletion mutants. In contrast to the full-length TLCN that was present in the ML and absent in the DCN (Fig. 3A), all of the three deletion mutants were observed in the DCN and ML (Fig. 3B-H) (data not shown). Even in the case of 12-amino acid deletion mutant (TLCN $\Delta \mathrm{C} 12$ ), its immunoreactivity was clearly detectable in the DCN (Fig. $3 F-H$ ), where axons of the Purkinje cells project. An observation at higher magnification of DCN sections double labeled with MAb271A6 and anti-calbindin antibody revealed that TLCN $\Delta \mathrm{C} 12$ was present at the axonal terminals of Purkinje cells, which surround large cell bodies of the DCN neurons (Fig. $3 I-K$ ). Thus, all of the deletion mutants of TLCN were distributed both in dendrites and axons of Purkinje cells, suggesting that the C-terminal region is necessary for the dendritic targeting of TLCN.

Next, we constructed TLCN/FLAG transgene in which a $3 x F L A G$ tag sequence was added at the $\mathrm{C}$ terminus of TLCN. TLCN/FLAG fusion protein was detected at axonal terminals in the DCN as well as on dendrites in the ML (Fig. $3 L-N$ ). Quantitative analysis revealed that the dendritic targeting was significantly attenuated by the addition of FLAG at the C terminus of TLCN (Fig. 2C). This result suggests that an open structure of the TLCN C terminus is important to execute selective targeting into dendrites.

\section{Phe905 of TLCN is crucial for dendritic targeting}

Aromatic amino acid residues, especially Tyr, have been reported to play a role as key residues in the dendritic sorting of several molecules (West et al., 1997; Jareb and Banker, 1998; Eiraku et al., 2002). The cytoplasmic region of TLCN contains only one Tyr at 861 and one Phe at 905. To examine whether these aromatic amino acids are important for the dendritic sorting, we constructed point mutants of TLCN for which Tyr861 or Phe905 were substituted to Ala (Fig. 2 B, TLCN-Y861A and TLCNF905A) and generated transgenic mouse lines. The TLCN-Y861A mutant showed dendrite-specific localization in Purkinje cells (Fig. 4A-C), similar to the full-length TLCN (Fig. 1). In contrast, the TLCN-F905A mutant was detected both in the dendrites and axons of Purkinje cells, exhibiting no preference of localization (Fig. 4D-F). These results suggest that Phe905, but not Tyr861, is important for the dendrite-specific targeting of TLCN. 


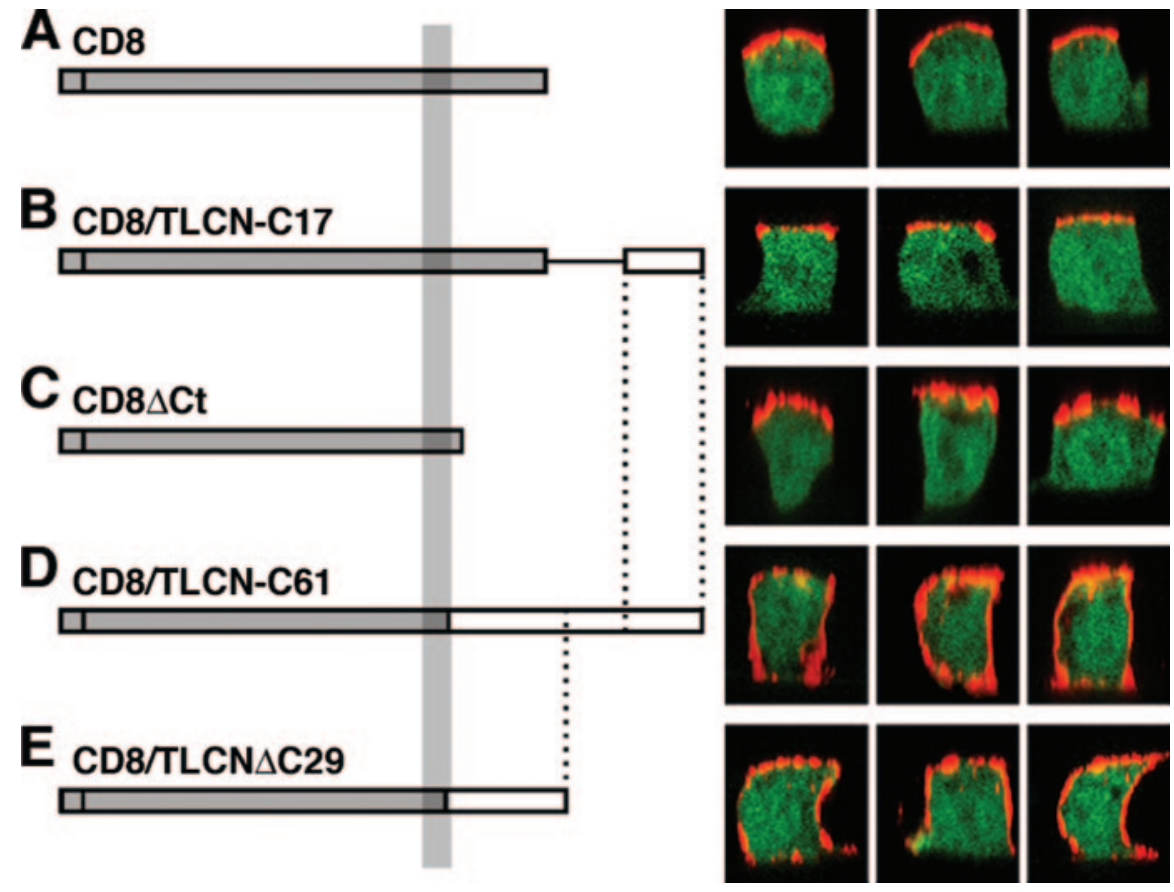

Figure 7. Dendritic targeting signal of TLCN does not mediate basolateral targeting in MDCK cells. Localization of CD8 and CD8/TLCN fusion proteins in polarized epithelial cells is shown. MDCK cells were transfected with plasmids expressing CD8 $(A)$ and its mutants $(B-E)$ together with EGFP and stained with anti-CD8 antibody (red). Right photographs show three representative confocal images for each construct in a vertical section (z-series), illustrating localization of CD8 immunoreactivity (red) and cytoplasmic GFP fluorescence (green). CD8 ( $A), \mathrm{CD} 8 / \mathrm{TLCN}-\mathrm{C17}(B)$, and CD8 $\Delta \mathrm{Ct}(\mathrm{C})$ are localized exclusively to the apical surface, whereas CD8/TLCN-C61 (D) and CD8/TLCN $\Delta C 29(E)$ are found in both apical and basolateral membranes.

\section{TLCN cytoplasmic region is sufficient for dendritic targeting} in Purkinje cells

To determine whether the cytoplasmic region of TLCN is sufficient to mediate dendritic targeting, we constructed a chimeric transgene (CD8/TLCN-C61) consisting of the extracellular and transmembrane regions of an unrelated immune molecule CD8 fused to the whole cytoplasmic region of TLCN (Fig. $2 B$ ). Native CD8 ectopically expressed in Purkinje cells was distributed both in axons and dendrites (Fig. 5A-C). In contrast, chimeric CD8/ TLCN-C61 was specifically localized to dendrites of Purkinje cells (Fig. 5D-F).

Because the deletion experiments revealed requirement for dendritic localization of the extreme $\mathrm{C}$ terminus of TLCN, we constructed another chimeric transgene, CD8/TLCN-C17, consisting of the full-length CD8 fused to the C-terminal 17 amino acids (AESPAGGEVFAIQLTSA) of TLCN (Fig. 2B). CD8/ TLCN-C17 was detected specifically in dendrites but not in axons (Fig. 5G-I). These results, together with those from the deletion and point mutant experiments (Figs. 3, 4), demonstrate that the 17 amino acid sequence at the $\mathrm{C}$ terminus fulfills both necessary and sufficient conditions for selective dendritic targeting of TLCN.

Figure $2 C$ summarizes a quantitative result of polarized distribution for all of the transgene products in Purkinje cells, as represented by the ADR. Transgene products containing the intact 17 amino acid sequence of TLCN cytoplasmic region showed selective appearance in dendrites (ADR, 0.02-0.1). In contrast, C-terminal deletion, FLAG addition, and F905A mutation resulted in no preference of localization in either dendrites or axons (ADR, 0.3-1.0).
TLCN cytoplasmic region is sufficient for dendritic targeting in telencephalic neurons

Because Purkinje cells are nontelencephalic neurons, we next asked whether the TLCN cytoplasmic region could function as a dendritic sorting signal in telencephalic neurons. To answer this question, we made use of the promoter/enhancer elements of mouse TLCN that can efficiently direct transgene expression in subpopulations of neurons in the telencephalon ( $\mathrm{S}$. Mitsui and Yoshihara, unpublished data). Native CD8 or chimeric CD8/TLCN-C61 was expressed by telencephalic neurons under the control of TLCN promoter (Fig. $6 A, B)$. We focused on two types of neurons for which axons could be clearly identified in these transgenic mice: granule cells in the hippocampal dentate gyrus (Fig. $6 \mathrm{C}-\mathrm{H}$ ) and medium spiny neurons in the caudate-putamen (Fig. 6I-N). The dentate gyrus granule cells project their axons (mossy fibers) to the CA3 area and extend their dendrites in the molecular layer, as visualized by immunostaining with anti-calbindin antibody (Fig. 6E,F) (Bagri et al., 2003). In the control CD8 transgenic mice, the immunoreactivity of CD8 was observed in both the mossy fibers and the molecular layer (Fig. 6C, $G$ ), suggesting the distribution of CD8 both in axons and in dendrites of granule cells. In the CD8/TLCN-C61 transgenic mice, in contrast, the immunoreactivity was detected in the molecular layer but not in the mossy fibers (Fig. 6D, H), indicating selective dendritic localization.

Medium spiny neurons in the caudate-putamen project their axons to the substantia nigra in midbrain and the globus pallidus in diencephalon that can be immunohistochemistry visualized using anti-substance P antibody (Fig. 6K,L) (Sun et al., 2002). TLCN promoter directed strong expression of transgenes (CD8 or CD8/TLCN-C61) in these neurons of caudate-putamen (Fig. $6 I, J)$. CD8 protein was found in axonal terminals in the substantia nigra and the globus pallidus (Fig. 6I,M), whereas CD8/ TLCN-C61 protein was not detected in these axons (Fig. $6 \mathrm{~J}, \mathrm{~N}$, arrows). These results demonstrate that the cytoplasmic region of TLCN can function as a dendritic targeting determinant not only in nontelencephalic cerebellar Purkinje cells but also in telencephalic neurons such as the dentate granule cells and the striatal medium spiny neurons.

TLCN dendritic targeting signal does not serve as basolateral targeting signal in polarized epithelial cells

It has been proposed that neurons and epithelial cells are equipped with common molecular machinery for selective sorting of proteins to their correct destinations: the axonal/apical membranes or the dendritic/basolateral membranes (Dotti and Simons, 1990; Craig and Banker, 1994; Winckler and Mellman, 1999). We examined whether the C-terminal 17 amino acid sequence of TLCN can serve as a basolateral-targeting signal in polarized epithelial cells. Because full-length TLCN expression in MDCK cells resulted in disruption of their monolayer organization (data not shown), we used CD8 and its fusion constructs 
with TLCN cytoplasmic region. MDCK cells were cultured on Transwell polyester filters at confluency and transfected with CD8 or CD8/TLCN chimeric constructs (Fig. 7). When observed in a plane vertical to the monolayer, wild-type CD8 was localized to the apical membrane of MDCK cells (Fig. 7A), as reported previously (Migliaccio et al., 1990). Addition of the dendritic sorting signal of TLCN (C-terminal 17 amino acids) to CD8 did not affect the apical targeting (Fig. $7 B$ ). In contrast, CD8/TLCNC61 consisting of the extracellular and transmembrane regions of CD8 fused to the whole cytoplasmic region of TLCN (61 amino acids) was detected to both the apical and basolateral surfaces (Fig. 7D). The basolateral appearance was also observed in the case of CD8/TLCNC $\Delta 29$, which contains the membraneproximal 32 amino acids of TLCN cytoplasmic region (Fig. 7E). These results suggest that the $\mathrm{C}$-terminal dendritic targeting signal of TLCN does not serve for basolateral sorting in polarized epithelial cells. However, there is a basolateral-targeting signal in the membrane-proximal region of TLCN cytoplasmic region that is distinct from the dendritic targeting signal.

\section{Discussion}

A transgenic mouse system for analysis of polarized targeting in neurons

To understand how neuronal proteins are targeted to their appropriate subcellular compartments such as dendrites and axons, we need a reliable assay system for protein trafficking in model neurons. Previous studies on polarized targeting of neuronal proteins have been performed with primarily cultured hippocampal neurons in vitro (Dotti and Simons, 1990; Craig and Banker, 1994; West et al., 1997; Jareb and Banker, 1998; Poyatos et al., 2000; Eiraku et al., 2002; Rivera et al., 2003; Silverman et al., 2004). In cultured hippocampal neurons, TLCN is expressed selectively in the somatodendritic compartment (Benson et al., 1998). The method with primarily cultured neurons has been useful and convenient in investigating a variety of constructs by simply transfecting the cultured neurons with the transgenes in a mammalian expression vector. However, the cultured neurons lack some of their differentiated properties (Boyer et al., 1998; De Simoni et al., 2003) and are surrounded by artificial environment in culture dishes. Therefore, we should be aware of interpreting the results obtained from this conventional assay method.

Our novel strategy makes use of in vivo neurons as a platform of protein trafficking and, thus, may minimize the artificial conditions. We chose Purkinje cells as a model neuron because of its characteristic morphology with elaborated spiny dendrites in the ML and a single long axon projecting to the DCN. The use of L7 gene promoter enabled us to express transgenes efficiently and specifically in Purkinje cells (Oberdick et al., 1990; Vandaele et al., 1991; Yoshihara et al., 1999). Using a standard immunohistochemical technique, we determined unequivocally whether the transgene products were localized to dendrites or not. Furthermore, establishment of transgenic mouse lines ensured the reproducibility of results.

We used the new transgenic assay system to investigate mechanisms for the dendritic sorting of TLCN. When the full-length TLCN was expressed in Purkinje cells, its immunoreactivity was localized to the ML but not to the GL, WM, and DCN (Fig. $1 D-K)$. The result indicates that TLCN underwent selective sorting into dendrites and coincides with our previous immunoelectron microscopic reports showing dendrite-specific localization of endogenous TLCN in telencephalic neurons (Murakami et al., 1991; Sakurai et al., 1998). Thus, Purkinje cells and telencephalic neurons share the same or similar molecular machineries for dendritic targeting of TLCN. In contrast, the lymphocyte mem- brane protein CD8 was found to distribute in both dendrites and axons of Purkinje cells (Fig. 5A-C) in good accordance with a previous report (Craig et al., 1995). Although we have not examined the selective targeting of axon-specific molecules by ectopically expressing in Purkinje cells, the new transgenic mouse system would be useful in examining the polarized neuronal targeting of any molecules of interest.

\section{A novel dendritic targeting motif at the cytoplasmic tail of TLCN}

In this study, we identified a 17 amino acid motif at the $\mathrm{C}$ terminus of TLCN that is necessary and sufficient for its specific localization to the dendritic compartment of neurons. The 17 amino acid residues are highly conserved among human, mouse, rat, and rabbit TLCN with only two amino acid substitutions (Fig. $2 A$ ). This sequence does not contain any canonical tyrosine- or dileucine-based motifs that have been identified as dendritic targeting signals in several membrane proteins (West et al., 1997; Jareb and Banker, 1998; Poyatos et al., 2000; Eiraku et al., 2002; Rivera et al., 2003). Instead, a point mutation of one amino acid, Phe905, resulted in abrogation of the dendrite-specific localization of TLCN, suggesting that the Phe905 is critical for the dendritic targeting. We thus propose a novel dendritic targeting signal that is based on a phenylalanine residue. We were unable to find any proteins containing a $\mathrm{C}$-terminal sequence homologous to that of TLCN by a database search (NCBI BLAST; search for short, nearly exact matches), but other sorting motifs shared by different proteins have proved difficult to identify solely on the basis of the amino acid sequence. We speculate the existence of a dendritic targeting mechanism shared by TLCN and other membrane proteins, because the machineries are equipped in the cerebellar Purkinje cells that do not express TLCN endogenously.

A previous study reported that addition of the 65 amino acid axonal targeting sequence of mGluR7 to the $\mathrm{C}$ terminus of TLCN induced appearance of the chimeric protein in both axons and dendrites and concluded that the axonal targeting signal of mGluR7 redirected the targeting of TLCN to axons (Stowell and Craig, 1999). In the present study, however, we showed that the addition of $3 x F L A G$ sequence to the $C$ terminus also resulted in attenuation of dendritic targeting of TLCN. We speculate that the addition of any amino acid sequences (including the axonal targeting sequence of mGluR7) masks the important "open" structure of TLCN cytoplasmic tail region and thus prevent the chimeric TLCN from the selective dendritic targeting.

Polarized epithelial cells and neurons are equipped with similar molecular and cellular machineries for protein targeting to distinct intracellular compartments (Dotti and Simons, 1990; Craig and Banker, 1994; Winckler and Mellman, 1999), although there are several exceptions (Ahn et al., 1996; Poyatos et al., 2000; Cheng et al., 2002). The dendritic and basolateral sorting shares many common features, as does the axonal and apical sorting. For example, a small GTPase Rab8 is involved in polarized protein transport to both the neuronal dendritic and epithelial basolateral membranes (Huber et al., 1993a,b). The Tyr-based motif in low-density lipoprotein receptor confers both the dendritic targeting in neurons and the basolateral targeting in polarized epithelial cells (Jareb and Banker, 1998). In the case of TLCN, however, the C-terminal 17 amino acid motif serves solely as a dendritic targeting signal in neurons but does not function as a basolateral targeting signal in epithelial cells. In contrast, the membrane-proximal domain of TLCN mediates only basolateral targeting but not dendritic targeting. Thus, the cytoplasmic region of TLCN would become a good model with which to study 
different molecular mechanisms underlying the dendritic targeting in neurons and the basolateral targeting in epithelial cells.

Several motor and cargo molecules mediate targeting of neuronal proteins to dendrites. They include Rab8 (Huber et al., 1993a,b), KIFC2 (Saito et al., 1997), KIF17 (Setou et al., 2000; Guillaud et al., 2003), AP-1 (Eiraku et al., 2002), and AP-4 (Yap et al., 2003). At present, it remains unknown what molecule interacts with the cytoplasmic tail of TLCN. Additional studies are necessary to identify an intracellular partner of TLCN that mediates its dendrite-specific localization.

When sorted to the dendritic surface membrane, TLCN plays important roles in the formation and maintenance of the dendritic filopodia (Matsuno, Mori, and Yoshihara, unpublished data), in the generation of long-term potentiation at hippocampal synapses (Sakurai et al., 1998; Nakamura et al., 2001), and in the development and plasticity of neuronal circuit in the visual cortex (M. Faglioni, Matsuno, Mori, Yoshihara, and T. K. Hensch, unpublished data). TLCN has a homophilic binding activity (Tian et al., 2000b). The homophilic adhesion of TLCN mediates induction of dendritic outgrowth (Tamada et al., 1998). TLCN can bind also to $\alpha \mathrm{L} \beta 2$ integrin [lymphocyte function-associated antigen-1 (LFA-1); CD11a/CD18] expressed by leukocytes and microglia. The binding between TLCN and LFA-1 may be important for the neuron/microglia or neuron/lymphocyte interactions under pathological conditions (Mizuno et al., 1997, 1999; Tian et al., 1997, 2000a). Thus, the knowledge of dendritic sorting of TLCN would provide an important basis for understanding the roles of TLCN in a variety of dendritic functions in the telencephalic neurons.

\section{References}

Ahn J, Mundigl O, Muth TR, Rudnick G, Caplan MJ (1996) Polarized expression of GABA transporters in Madin-Darby canine kidney cells and cultured hippocampal neurons. J Biol Chem 271:6917-6924.

Altman J, Bayer SA (1996) Development of the cerebellar system: In: Relation to its evolution, structure, and functions, pp 26-43. Boca Raton, FL: CRC.

Bagri A, Cheng HJ, Yaron A, Pleasure SJ, Tessier-Lavigne M (2003) Stereotyped pruning of long hippocampal axon branches triggered by retraction inducers of the semaphorin family. Cell 113:285-299.

Benson DL, Yoshihara Y, Mori K (1998) Polarized distribution and cell type-specific localization of telencephalin, and intercellular adhesion molecule. J Neurosci Res 52:43-53.

Boyer C, Schikorsk T, Stevens CF (1998) Comparison of hippocampal dendritic spines in culture and in brain. J Neurosci 18:5294-5300.

Cheng C, Glover G, Banker G, Amara SG (2002) A novel sorting motif in the glutamate transporter excitatory amino acid transporter 3 directs its targeting in Madin-Darby canine kidney cells and hippocampal neurons. J Neurosci 15:10643-10652.

Craig AM, Banker G (1994) Neuronal polarity. Annu Rev Neurosci $17: 267-310$

Craig AM, Wyborski RJ, Banker G (1995) Preferential addition of newly synthesized membrane protein at axonal growth cones. Nature 375:592-594.

De Simoni A, Griesinger CB, Edwards FA (2003) Development of rat CA1 neurones in acute versus organotypic slices: role of experience in synaptic morphology and activity. J Physiol (Lond) 550:135-147.

Dotti CG, Simons K (1990) Polarized sorting of viral glycoproteins to the axon and dendrites of hippocampal neurons in culture. Cell 62:63-72.

Eiraku M, Hirata Y, Takeshima H, Hirano T, Kengaku M (2002) Delta/ Notch-like epidermal growth factor (EGF)-related receptor, a novel EGFlike repeat-containing protein targeted to dendrites of developing and adult central nervous system neurons. J Biol Chem 277:25400-25407.

Guillaud L, Setou M, Hirokawa N (2003) KIF17 dynamics and regulation of NR2B trafficking in hippocampal neurons. J Neurosci 23:131-140.

Huber LA, de Hoop MJ, Dupree P, Zerial M, Simons K, Dotti C (1993a) Protein transport to the dendritic plasma membrane of cultured neurons is regulated by rab8p. J Cell Biol 123:47-55.
Huber LA, Pimplikar S, Parton RG, Bhakdi S, Simons K (1993b) Rab8, a small GTPase involved in vesicular traffic between the TGN and the basolateral plasma membrane. J Cell Biol 123:35-45.

Jareb M, Banker G (1998) The polarized sorting of membrane proteins expressed in cultured hippocampal neurons using viral vectors. Neuron 20:855-867.

Kobayashi K, Morita S, Mizuguchi T, Sawada H, Yamada K, Nagatsu I, Fujita K, Nagatsu T (1994) Functional and high level expression of human dopamine $\beta$-hydroxylase in transgenic mice. J Biol Chem 269:29725-29731.

Migliaccio G, Zurzolo C, Nitsch L, Obici S, Lotti LV, Torrisi MR, Pascale MC, Leone A, Bonati S (1990) Human CD8 $\alpha$ glycoprotein is expressed at the apical plasma membrane domain in permanently transformed MDCK II clones. Eur J Cell Biol 52:291-296.

Mizuno T, Yoshihara Y, Inazawa J, Kagamiyama H, Mori K (1997) cDNA cloning and chromosomal localization of the human telencephalin and its distinctive interaction with lymphocyte function-associated antigen-1. J Biol Chem 272:1156-1163.

Mizuno T, Yoshihara Y, Kagamiyama H, Ohsawa K, Imai Y, Kohsaka S, Mori K (1999) Neuronal adhesion molecule telencephalin induces rapid cell spreading of microglia. Brain Res 849:58-66.

Mori K, Fujita SC, Watanabe Y, Obata K, Hayaishi O (1987) Telencephalonspecific antigen identified by monoclonal antibody. Proc Natl Acad Sci USA 84:3921-3925.

Murakami F, Tada T, Mori K, Oka O, Katsumaru H (1991) Ultrastructural localization of telencephalin, a telencephalon-specific membrane glycoprotein, in rabbit olfactory bulb. Neurosci Res 11:141-145.

Nakamura K, Manabe T, Watanabe M, Mamiya T, Ichikawa R, Kiyama Y, Sanbo M, Yagi T, Inoue Y, Nabeshima T, Mori H, Mishina M (2001) Enhancement of hippocampal LTP, reference memory and sensorimotor gating in mutant mice lacking a telencephalon-specific cell adhesion molecule. Eur J Neurosci 13:179-189.

Oberdick J, Smeyne RJ, Mann JR, Zackson S, Morgan JI (1990) A promoter that drives transgene expression in cerebellar Purkinje and retinal bipolar neurons. Science 248:223-226.

Oka S, Mori M, Watanabe Y (1990) Mammalian telencephalic neurons express a segment-specific membrane glycoprotein, telencephalin. Neuroscience 35:93-105.

Poyatos I, Ruberti F, Martinez-Maza R, Gimenez C, Dotti CG, Zafra F (2000) Polarized distribution of glycine transporter isoforms in epithelial and neuronal cells. Mol Cell Neurosci 15:99-111.

Rivera JF, Ahmad S, Quick MW, Liman ER, Arnold DB (2003) An evolutionarily conserved dileucine motif in Shal $\mathrm{K}^{+}$channels mediates dendritic targeting. Nat Neurosci 6:243-250.

Saito N, Okada Y, Noda Y, Kinoshita Y, Kondo S, Hirokawa N (1997) KIFC2 is a novel neuron-specific C-terminal type kinesin superfamily motor for dendritic transport of multivesicular body-like organelles. Neuron 18:425-438.

Sakurai E, Hashikawa T, Yoshihara Y, Kaneko S, Satoh M, Mori M (1998) Involvement of dendritic adhesion molecule telencephalin in hippocampal long-term potentiation. NeuroReport 9:881-886.

Setou M, Nakagawa T, Seog DH, Hirokawa N (2000) Kinesin superfamily motor protein KIF17 and mLin-10 in NMDA receptor-containing vesicle transport. Science 288:1796-1802.

Silverman MA, Kaech S, Jareb M, Burack MA, Vogt L, Sonderegger P, Banker G (2004) Sorting and directed transport of membrane proteins during development of hippocampal neurons in culture. Proc Natl Acad Sci USA 98:7051-7057.

Stowell JN, Craig AM (1999) Axon/dendritic targeting of metabotropic glutamate receptors by their cytoplasmic carboxy-terminal domains. Neuron 22:525-536.

Sugino H, Yoshihara Y, Copeland NG, Gilbert DJ, Jenkins NA, Mori K (1997) Genomic organization and chromosomal localization of the mouse telencephalin gene, a neuronal member of the ICAM family. Genomics 43:209-215.

Sun Z, Del Mar N, Meade C, Goldowitz D, Reiner A (2002) Differential changes in striatal projection neurons in R6/2 transgenic mice for Huntington's disease. Neurobiol Dis 11:369-385.

Tamada A, Yoshihara Y, Mori K (1998) Dendrite-associated cell adhesion molecule, telencephalin, promotes neurite outgrowth in mouse embryo. Neurosci Lett 240:163-166.

Tian L, Yoshihara Y, Mizuno T, Mori K, Gahmberg CG (1997) The neuro- 
nal glycoprotein telencephalin is a cellular ligand for the CD11a/CD18 leukocyte integrin. J Immunol 158:928-936.

Tian L, Kilgannon P, Yoshihara Y, Mori K, Gallatin WM, Carpen O, Gahmberg CG (2000a) Binding of T lymphocytes to hippocampal neurons through ICAM-5 (telencephalin) and characterization of its interaction with the leukocyte integrin CD11a/CD18. Eur J Immunol 30:810-818.

Tian L, Nyman H, Kilgannon P, Yoshihara Y, Mori K, Andersson LC, Kaukinen S, Rauvala H, Gallatin WM, Gahmberg CG (2000b) Intercellular adhesion molecule- 5 induces dendritic outgrowth by homophilic adhesion. J Cell Biol 150:243-252.

Vandaele S, Nordquist DT, Feddersen RM, Tretjakoff I, Peterson AC, Orr HT (1991) Purkinje cell protein-2 regulatory regions and transgene expression in cerebellar compartments. Genes Dev 5:1136-1148.

West AE, Neve RL, Buckley KM (1997) Identification of a somatodendritic targeting signal in the cytoplasmic domain of the transferring receptor. J Neurosci 17:6038-6047.
Winckler B, Mellman I (1999) Neuronal polarity: controlling the sorting and diffusion of membrane components. Neuron 23:637-640.

Yap CC, Motohide M, Kishigami S, Muto Y, Kishida H, Hashikawa T, Yano R (2003) Adaptor protein complex-4 (AP-4) is expressed in the central nervous system neurons and interacts with glutamate receptor $\delta 2$. Mol Cell Neurosci 24:283-295.

Yoshihara Y, Mori K (1994) Telencephalin: a neuronal area code molecule? Neurosci Res 21:119-124.

Yoshihara Y, Oka S, Nemoto Y, Watanabe Y, Nagata S, Kagamiyama H, Mori K (1994) An ICAM-related neuronal glycoprotein, telencephalin, with brain segment-specific expression. Neuron 12:541-553.

Yoshihara Y, Mizuno T, Nakahira M, Kawasaki M, Watanabe Y, Kagamiyama H, Jishage K, Ueda O, Suzuki H, Tabuchi K, Sawamoto K, Okano H, Noda T, Mori M (1999) A genetic approach to visualization of multisynaptic neural pathways using plant lectin transgene. Neuron 22:33-41. 